\title{
Quilombo Mata Cavalo: os conflitos agrários e a violação do direito humano ao território étnico em Nossa Senhora do Livramento-MT
}

\author{
Thaisa Maira Rodrigues Held \\ Universidade Federal de Mato Grosso
}

Resumo: O presente trabalho tem por objetivo a análise dos conflitos agrários no Quilombo Mata Cavalo localizado em Nossa Senhora do Livramento-MT e de que modo o Estado brasileiro viola o direito humano ao território quilombola consagrado pelo ordenamento jurídico interno e internacional.

Palavras-chave: Conflitos agrários; Quilombo Mata Cavalo; direito humano; território. 


\title{
Quilombo Mata Caballo: los conflictos agrarios y la violación del derecho humano al territorio étnico em Nuestra Señora del Livramento-MT
}

\begin{abstract}
Resumen: El presente trabajo tiene por objetivo el análisis de los conflictos agrarios em el Quilombo Mata Caballo ubicado em Nuestra Senõra del Livramento-MT y de qué modo el Estado brasileño viola el derecho humano al territorio quilombola consagrado por el ordenamiento jurídico interno e internacional.
\end{abstract}

Palabras clave: Conflictos agrarios; Quilombo Mata Caballo; derecho humano; territorio.

\section{Quilombo Mata Cavalo: the agrarian conflictos and the violation of the human right to the ethnic territory in Nossa Senhora do Livramento-MT}

\begin{abstract}
The presente work has the objective of analyzing the agrarian conflicts in Quilombo Mata Cavalo located in Nossa Senhora do Livramento-MT and how the Brazilian State violates the human right to the quilombola territory consecrated by the internal and international legal order.
\end{abstract}

Keywords: Agrarian conflicts; Quilombo Mata Cavalo; human right; territory. 


\section{Introdução}

As violações de direitos humanos dos quilombolas no Brasil ocorrem desde a diáspora de seus antepassados que, arrancados do Continente Africano vieram pelo Atlântico em navios negreiros e foram escravizados nas plantações e engenhos de cana-de-açúcar em solo brasileiro pelos colonizadores, especialmente os portugueses.

Subjugados a coisas, seus corpos eram considerados apenas insumos de trabalho e foram o combustível para a expansão do sistema de capital europeu. Suas almas só poderiam ser salvas mediante o sacrifício no labor escravo; construção ideológica inserida pelos jesuítas da Igreja Católica, que endossou o sistema escravista e contribuiu para a formação de classes desigual e a todo o momento tentou anular as identidades étnicas dos africanos.

Apesar da subjugação, os negros escravizados possuíam duas características essenciais: a manutenção de suas raízes étnicas e a revolta pelo sistema opressor, responsáveis pela resistência ao açoite e pela reconstrução de seus modos de ser, fazer e viver. Os quilombos, formações históricas de resistência ao sistema escravista, fazem parte da maior história de violação de direitos humanos do Brasil que durou mais de trezentos e cinquenta anos.

Tornaram-se cenários de convívio e de práticas culturais de diversas etnias africanas que aos poucos resgatavam suas identidades e juntavam fragmentos que eram vivos na memória antes de sua escravização.1 Mas também representavam uma constante ameaça à estrutura de plantation e à própria ordem social imposta pelos portugueses, pois à medida que as fugas ocorriam, o déficit de mão de obra diminuía, ao tempo em que a violência empregada à captura dos "negros fujõos" era cada vez maior.

O processo abolicionista foi gradativo, de modo que não há um rompimento do tráfico negreiro com a Lei Feijó, tampouco a efetiva libertação dos negros com a Lei n. 3.353, de 13 de maio de 1888. O período de ilegalidade da subjugação do negro não trouxe, no entanto, sua condição de cidadão, uma vez que o processo de marginalização e exclusão, pois ser negro "[...] englobava, a experiência histórica dos africanos e seus descendentes, tratados nos séculos anteriores como sujeitos a-históricos, negados em sua condição de humanidade durante o regime escravista." (LEITE, 1999: 131)

A liberdade, tão almejada pelos abolicionistas, no entanto, não sanou as condições de vulnerabilidade social, especialmente no pertinente ao acesso à terra. Mesmo com a suspensão do regime de sesmarias em 1822, esta continuou a existir na prática, uma vez que os latifundiários, receosos de perder mão de obra, arquitetaram formas de não permitir aos quilombolas a posse de terras. $\mathrm{O}$

\footnotetext{
1 As diversas etnias vindas do Continente Africano trouxeram contribuições diversas conforme as variações linguísticas e culturais. Nesse sentido, ver MENDONÇA, Renato. A influência africana no português do Brasil. 2 ed. São Paulo: Companhia Editora Nacional, 1935.
} 
"Império de posses" comandado pelos latifundiários, além de excluir o negro pobre, formou as oligarquias rurais brasileiras. (ALCÂNTARA; FONTES, 2009: 66).

Como parte das manobras excludentes, a Lei n. 601, de 18 de setembro de 1850 trata da aquisição de terras devolutas mediante a compra, o que somente era possível aos grandes posseiros em um "[...] processo perverso de afastamento jurídico do negro à propriedade da terra.” (BANDEIRA, 1991: 7).

A legislação brasileira manteve por décadas o sistema de classes imposto pelos escravizadores, uma vez que os negros, tolhidos em seu direito ao acesso à terra, foram mantidos à margem da sociedade, pois a liberdade não lhes garantiu a cidadania.

Somente em 1988, com a promulgação da Constituição Federal e por meio da luta dos movimentos negros é que foi inserido o artigo 68 no Ato das Disposições Constitucionais Transitórias (ADCT) reconhecendo o direito aos territórios quilombolas e o dever do Estado de efetivá-lo. A transitoriedade significou a ideia de existência de "poucos remanescentes de quilombos" do imaginário social.

É preciso compreender que há um aparato jurídico composto por normas que reconhecem os direitos humanos dos quilombolas, tomando como exemplos o direito ao território, à preservação e promoção das manifestações culturais, à saúde e acesso à justiça. Somados às normas os princípios basilares como o da dignidade humana. Deste modo, falar em direitos humanos dos quilombolas é tornar efetivos os direitos formalmente reconhecidos.

Não obstante, ao não se efetivar tais direitos, o Estado brasileiro possibilita que conflitos de interesses em territórios quilombolas ocorram cotidianamente. Nesse sentido, o presente trabalho, fruto da pesquisa doutoral em Direito busca refletir sobre as tensões pela terra no Quilombo Mata Cavalo e de que modo a dignidade humana tem sido violada.

\section{A proteção do território quilombola no sistema de direitos humanos}

O território quilombola é por vezes ignorado em seu real sentido pelo jurista. Sua compreensão deve transcender o sentido individual e material da terra e é necessário que se considere os aspectos identitários dos quilombolas em sua relação intrínseca com o quilombo.

Imprescindível socorrermo-nos das demais áreas do conhecimento, tais como Antropologia Social e História, sem as quais a ciência jurídica não pode se sustentar, de modo que não há como efetivar os direitos dos quilombolas sem a compreensão da realidade. Nesse sentido, a Carta de Ponta das Canas (ABA, 2000: 4) chama atenção para as tensões entre o direito e as demais ciências: 
objetiva de um ordenamento jurídico nacional ou realizar descrições densas da realidade local, que dificilmente podem fugir de suas aplicações contextuais;

Deste modo, o jurista deve transcender o tecnicismo que engessa interpretações distantes das realidades sociais dos quilombolas, sobretudo quanto à noção de terra tradicionalmente ocupada.

Este espaço de significados e toda a construção histórica definem a cultura, pois esta corresponde a um sistema estruturado de símbolos e significados que são transmitidos historicamente e que definem o próprio modo de vida. (BELTRÃO; OLIVEIRA, 2011: 58).

A peculiaridade dos modos de ser, fazer e viver dos quilombolas pressupõe que o território possui sentido imaterial traduzido no sentido de territorialidade, em práticas cotidianas de sobrevivência física e espiritual, uma vez que "[...] o movimento, uso e saber desenvolvidos sobre esse espaço, elaborados ao longo do tempo pelos negros, constroem sua representação de territorialidade." (ACEVEDO MARIN, 1995: 30-31). Explica Maria de Lourdes Bandeira (1991: 8) que: "a territorialidade das comunidades negras é referida na identidade étnica de cada grupo que as constitui. A posse da terra, independente das suas origens patrimoniais, se efetiva pelas comunidades negras enquanto sujeito coletivo [...]”. Desse modo, não se trata da relação entre pessoas físicas ou uso da terra individual.

Complementa Alfredo Wagner Berno de Almeida que os territórios quilombolas:

[...] compreendem, pois, uma constelação de situações de apropriação de recursos naturais (solos, hídricos e florestais), utilizados segundo uma diversidade de formas e com inúmeras combinações diferenciadas entre uso e propriedade e entre o caráter privado e comum, perpassadas por fatores étnicos, de parentesco e sucessão, por fatores históricos, por elementos identitários peculiares e por critérios políticoorganizativos e econômicos, consoante práticas e representações próprias. (2002: 45)

A constatação de que os territórios negros possuem significados diversos das terras utilizadas por não quilombolas e até mesmo outros grupos étnicos exige que o sistema jurídico dê proteção especial a fim de proteger a dignidade humana. Não obstante as dificuldades de interpretação do que seja quilombo e quilombola é possível afirmar que o território étnico é reconhecido pelo sistema de direitos humanos como fundamental à dignidade humana.

Há um sistema de proteção especial dos direitos humanos formado por tratados internacionais que visam reconhecer e efetivar o direito ao território étnico2 e demais consectários da dignidade, assim como é possível considerar que o Brasil possui uma estrutura jurídica de proteção a estes direitos.

É importante ressaltar que o direito à terra por vezes é encontrado nos tratados internacionais de direitos humanos como direito de propriedade. No entanto, seu conteúdo refere-se ao direito ao território, considerando ainda os usos coletivos e étnicos da terra, com abordagens que consideram o direito à integridade cultural, religiosa, todos eles correlatos à proteção do território étnico. (GILBERT, 2013: 126).

2 Em alguns momentos utilizaremos os termos "direito à terra", "direito ao território quilombola", "direito ao território étnico" ou "direito ao território", todos eles com o mesmo significado. 
Esta afirmação é claramente observada pelo artigo 17, 1 da Declaração Universal dos Direitos Humanos (DUDH): "Toda pessoa tem direito à propriedade, só ou em sociedade com outros. 2. Ninguém será arbitrariamente privado de sua propriedade." (DUDH, 1948).

Em complemento à Declaração3 e diante da necessidade de tornar com efeito jurídico o reconhecimento dos direitos humanos, o Pacto Internacional dos Direitos Civis e Políticos (PIDCP) tratou em seu artigo 27 do direito à não privação dos aspectos imateriais das minorias étnicas.

Encontramos também a proteção do território na Convenção Internacional sobre a Eliminação de todas as Formas de Discriminação Racial, pois no artigo $\mathrm{V}$ proíbe a discriminação étnico-racial e na alínea "v)" assegura o direito humano ao território, sendo "direito de qualquer pessoa, tanto individualmente como em conjunto, à propriedade.” (ONU, 1948)

Com maior repercussão internacional, a Convenção n. 169 da Organização Internacional do Trabalho sobre Povos Indígenas e Tribais prevê a proteção jurídica das terras de quilombo, referindo-se aos quilombolas como tribais no artigo $1^{\circ}$ cujas "[...] condições sociais, culturais e econômicas os distingam de outros setores da coletividade nacional, e que estejam regidos, total ou parcialmente, por seus próprios costumes ou tradições ou por legislação especial." (ONU, 1948)

A Convenção n. 169 da OIT reconhece a autodeterminação dos quilombolas, envolvendo o direito de escolha na organização e desenvolvimento de seus modos de vida, "[...] bem como as terras que ocupam ou utilizam de alguma forma, e de controlar, na medida do possível, o seu próprio desenvolvimento econômico, social e cultural." Todos os documentos internacionais mencionados foram ratificados pelo Brasil e internalizados no ordenamento jurídico por meio de decretos, devendo o país o seu fiel cumprimento.

Em âmbito nacional, o reconhecimento e a proteção dos territórios quilombolas estão dispostos no artigo 68 do Ato das Disposições Constitucionais Transitórias (ADCT) com a seguinte redação: [...] é reconhecida a propriedade definitiva, devendo o Estado emitir-lhes os títulos respectivos." Inobstante este direito tenha sido inserido em dispositivo transitório, este se mantém até os dias atuais, pois conforme observa Girolamo Treccani (2006: 84): "[...] o artigo tem eficácia plena, vinculando as comunidades remanescentes de quilombo ao seu território étno-sócio-cultural."

A fim de tornar efetivo o direito ao território quilombola, foi publicado o Decreto n. 3.912/2001. No entanto, referida norma não comtemplou todos os territórios quilombolas, uma vez que só reconhecia aqueles que estivessem sido ocupados pelas comunidades, ignorando situações de expropriações, assim como não previu indenização.

\footnotetext{
3 Importante observar que a Declaração Universal dos Direitos Humanos não é um tratado internacional e sim uma Resolução da Assembleia-Geral da Organização das Nações Unidas. No entanto, é o documento basilar de todo o sistema global e regional de direitos humanos.
} 
Em substituição ao decreto de 2001, foi instituído o de n. 4.887/2003, que atribui ao Instituto Nacional de Colonização e Reforma Agrária (INCRA) a competência em âmbito federal para a titulação, não obstante as competências estaduais e municipais.

Para Solazzi e Wolkmer (2016: 37) o Decreto: "viabilizou-se, efetivamente, a emergência de processos socioculturais de autorreconhecimento, percepção e identificação étnicas que permitiram o crescimento exponencial do número de certificações." Isto porque em consonância com o artigo 68 do ADCT, o legislador garantiu nos artigos 215 e 216 da Constituição Federal de 1988 a proteção das manifestações culturais e dos locais destinados para tal finalidade.

É importante ressaltar que o sistema de direitos humanos corresponde à estrutura normativa internacional, ou seja, a DUDH e os tratados internacionais e à estrutura jurídica nacional, quer seja, a Constituição Federal e as normas infraconstitucionais.

Todo o rol de direito age em complementaridade, em atendimento à primazia do ser humano, uma vez que "[...] vem atender uma das grandes preocupações de nossos tempos: assegurar a proteção do ser humano, nos planos nacional e internacional, em toda e qualquer circunstância." (CANÇADO TRINDADE, 2003: 39)

Desse modo, podemos considerar que há uma estrutura jurídica razoável que reconhece o território quilombola como essencial ao mínimo existencial humano e que de modo algum deve ser violado pelo Estado e pela sociedade.

\section{As tensões pela terra em Mata Cavalo e as violações de direitos humanos}

Constituído há aproximadamente cento e trinta e quatro anos, o Quilombo Mata Cavalo é formado por um grupo de negros que foram escravizados pelos antigos senhores da Sesmaria Boa Vida. Trata-se de uma doação de parte da sesmaria formalizada a termo4. Destoante da concepção comum de quilombo, Mata Cavalo é formado por herança, caracterizando a ocupação pacífica e não de refúgio, pois "[...] existe uma concessão de terras de herança que determina a linha da história comunicada pelos antepassados dos grupos em questão." (ACEVEDO MARIN; CASTRO, 2004: 17)

A territorialidade negra é caracterizada pelos modos de viver tradicionais a exemplo da agricultura de subsistência e a forma de trabalho coletiva, denominada muxirum, pois "[...] como bem coletivo, trabalhava-se a terra de acordo com as possibilidades da força-de-trabalho familiar." (BANDEIRA; SODRÉ; DANTAS, 2006: 104-105), assim como as festividades e manifestações religiosas, como a Festa do Congo, de São Benedito e Nossa Senhora da

\footnotetext{
4 O Termo de Doação, registrado em 15 de setembro de 1883 misteriosamente desapareceu. No entanto, há cópia deste documento nos arquivos do Instituto de Terras de Mato Grosso (INTERMAT) em que a senhora Ana da Silva Tavares doa parte da Sesmaria Boa Vida aos negros. Nesse sentido, ver HELD,
} 
Conceição. A utilização coletiva de instrumentos para produção de polvilho também é determinante para a identidade cultural. (HELD, 2017: 170)

Apesar do território ter sido objeto de doação, os quilombolas de Mata Cavalo vivem em situação de vulnerabilidade, uma vez que a partir da década de 1930, com a implantação da política nacional denominada "Marcha para o Oeste", além da invasão de posseiros, houve o esbulho de suas terras, que passaram a ser valorizadas. Registre-se que o quilombo situa-se na área central de Nossa Senhora do Livramento-MT, atualmente às margens da rodovia federal BR 060, o que facilita o interesse pelo local:

\begin{abstract}
[...] a territorialidade negra de Mata Cavalo foi duramente atingida sofrendo uma ofensiva de grilagem que encontrou a comunidade despreparada para reagir, uma vez que sempre valorizou o direito consuetudinário como instrumento suficiente para dirimir dúvidas sobre limites de terras ou resolver conflitos. [...] Como a maioria das propriedades do lugar, não tinha cercas. A inexistência de uma rígida demarcação da área não invalidava a posse histórica da terra, nem tampouco o reconhecimento da área como terra de negros de Mata Cavalo. (BANDEIRA; SODRÉ; DANTAS, 2006: 113-114)
\end{abstract}

A ocupação das terras por grileiros marca a desestruturação do quilombo, uma vez que muitos negros, sobretudo os jovens, direcionaram-se para as cidades vizinhas, como Várzea Grande, Cuiabá e Poconé fugindo das ameaças dos invasores e em busca de melhores condições de vida. (BARROS, 2007: 2.380)

Todavia, a resistência se fazia presente em Mata Cavalo. Algumas famílias permaneceram no território mesmo sob ameaças e todo o tipo de violência contra eles empregada. O constante movimento de expulsão e tentativa de retorno dos negros em suas terras permanece até os dias atuais, assim como os conflitos existentes no local.

Com a promulgação da Constituição Federal em 5 de outubro de 1988 e a inserção do artigo 68 do ADCT, os quilombolas viram brotar a esperança pelo reconhecimento de suas terras, uma vez que pela primeira vez foi inserido este direito na legislação brasileira.

Em 23 de abril de 1998 o governo de Mato Grosso editou o Decreto n. 2.205 reconhecendo o território quilombola. Neste mesmo ano, o INTERMAT arrecadou duas glebas via discriminatória e outorgou à Fundação Cultural Palmares (FCP) para que este órgão pudesse agilizar a titulação de parte das terras de Mata Cavalo.

De fato, a FCP reconheceu a área de 11.722,4613 hectares e expediu o Título de Reconhecimento de Domínio às comunidades quilombolas. Entretanto, o documento não foi registrado em Cartório pela recusa da tabeliã sob a justificativa de que além do não cumprimento de formalidades, havia a sobreposição de imóveis de terceiros.

Tão logo foi publicado o Decreto n. 4.887/2003, que trata da regulamentação do artigo 68 do ADCT, especificando os procedimentos para o reconhecimento e titulação das terras de quilombo, os quilombolas de Mata Cavalo organizaram-se uma associação denominada Associação Sesmaria Boa 
Vida Quilombo Mata Cavalo e protocolizaram o primeiro requerimento administrativo junto ao INCRA para tal finalidade 5

À medida que a legislação nacional e o Estado de Mato Grosso foi reconhecendo os direitos territoriais dos quilombolas de Mata Cavalo, a onda de violência aumentava, sobretudo após a abertura do processo administrativo de reconhecimento e titulação no INCRA, uma vez que os proprietários de terras inseridas no perímetro do quilombo reivindicam a legitimidade de sua propriedade, ao tempo que transações de compra e venda são feitas cotidianamente por posseiros.

Como forma de intimidação dos negros, os posseiros ateiam fogo em roçados e casas, quebram equipamentos de trabalho, cometem todo o tipo de ameaça aos quilombolas, além de impedirem que estes tenham acesso a locais sagrados, como cemitérios em que se encontram enterrados seus ancestrais.

A vulnerabilidade socioambiental dos quilombolas se demonstra também pela heterogeneidade do local, uma vez que habitam no perímetro de seu território famílias do Movimento Sem Terra (MST), além de proprietários com fortes influências políticas na região, que utilizam as áreas de forma predatória ocasionando diversos impactos ambientais, como queimadas, desmatamentos, contaminação da água e do solo pelas atividades de garimpo e despejos de lixo. (SATO et al., 2010: 32)

As tensões pela terra em Mata Cavalo transcenderam o âmbito administrativo e foram judicializadas, a exemplo das Ações Civis Públicas (ACP) n. 2002.36.00.006620-8, n. 2003.36.00.008934, e n. 2003.36.00.007491-8 propostas pelo Ministério Público Federal (MPF), em trâmite na Justiça Federal de Cuiabá-MT, cujo objeto é o reconhecimento do quilombo e sua titulação cujo termo de doação de parte da sesmaria é a pedra angular para a comprovação da posse histórica dos negros.

De um lado, o requerimento de reconhecimento do território quilombola e de outro, mas diversas manifestações e ajuizamentos de novas demandas de proprietários reivindicando o que entendem de direito.

Ao tempo que as discussões administrativas e judiciais ocorrem, as ameaças à dignidade humana dos quilombolas são latentes e demandam uma resposta do Estado brasileiro para que o direito reconhecido no plano formal seja garantido de fato.

As violações aos direitos humanos chamaram atenção a nível internacional e em 15 de agosto de 2004 o Relator Nacional para o Direito Humano ao Meio Ambiente esteve em visita no quilombo Mata Cavalo para averiguar o descaso do Estado. Como fruto das constatações, o relatório constatou que:

Enquanto a situação da área não é resolvida, há famílias inteiras morando em barracos de palha a poucos metros do asfalto, entre a rodovia e a cerca de fazendeiros que se apossaram da terra e impedem a entrada dos quilombolas. Apesar de haver

\footnotetext{
5 Processo administrativo INCRA/SR-13/N. 54240.001538/2004-70 em trâmite desde 13 de agosto de 2004 na Superintendência Regional do INCRA, em Cuiabá-MT. Atualmente o processo de regularização fundiária encontrase em fase de desapropriações dos imóveis de terceiros no interior do quilombo, assim como de desintrusão das famílias de não quilombolas que preenchem ou não o perfil da reforma agrária. Trata-se da fase mais demorada em delicada, pois envolvem interesses dos ditos proprietários.
} 
córregos na área cercada, as famílias são obrigadas a fazer um poço na terra e dali tirar água contaminada para beber e preparar alimentos. (DHESC Brasil, 2015: 22)

A fotografia a seguir registra os conflitos vivenciados em Mata Cavalo, como a expulsão de famílias do quilombo, a utilização da força policial, a construção precária de casa às margens da BR 060 e sobretudo a distorção da realidade ao se considerar o despejo em uma fazenda, e não a expropriação do território quilombola.

Fotografia 1 - Manchetes de jornas sobre casos de violência em Mata Cavalo

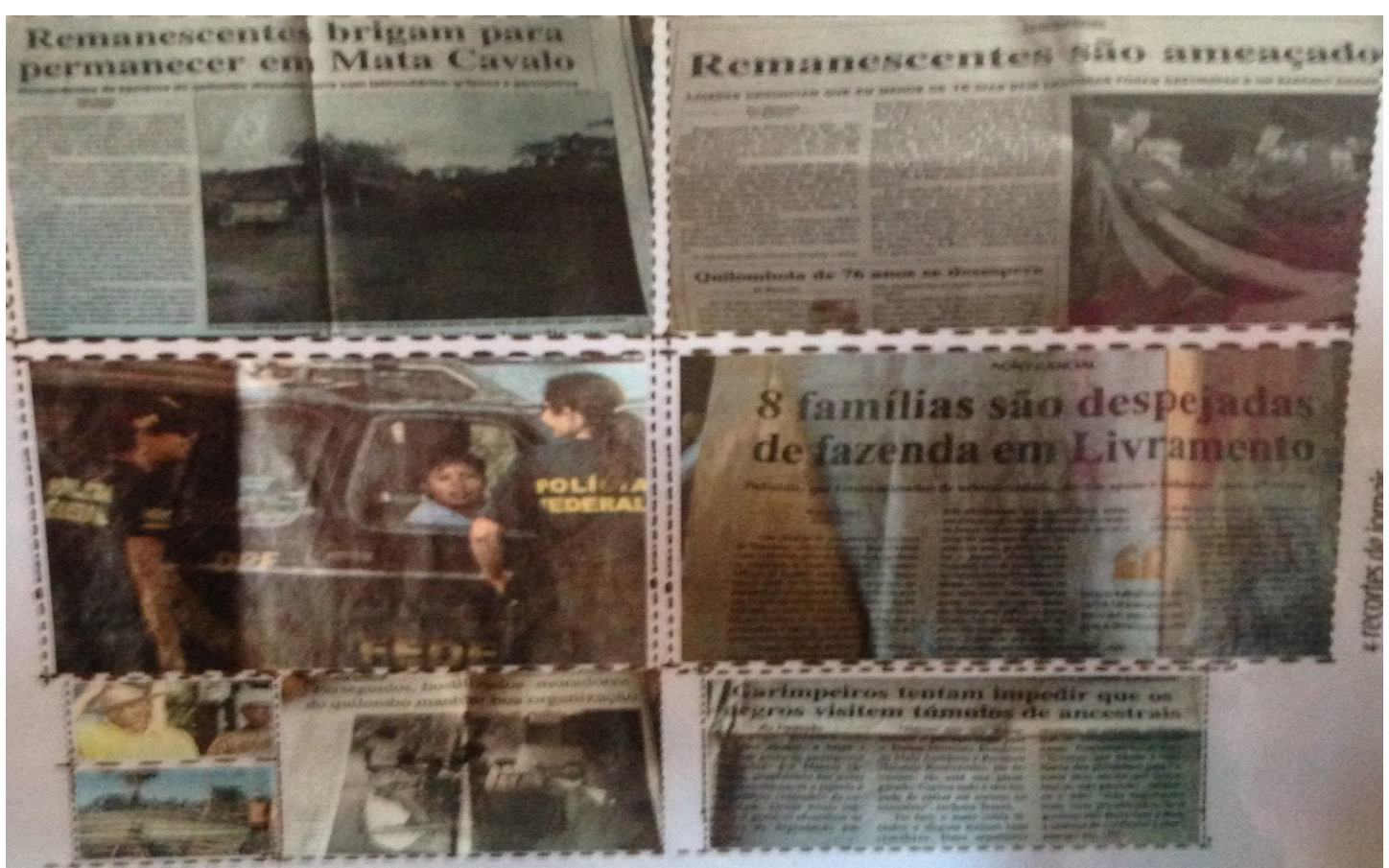

Fonte: registrada pela autora em Casa da Cultura Comunidade Quilombola Mata Cavalo

A análise da situação em que se encontram os quilombolas de Mata Cavalo permite considerar que mesmo com a estrutura jurídica internacional e interna que reconhece o direito humano ao território, com a organização do Estado brasileiro em promover a política pública de reconhecimento e titulação das terras de quilombo por meio das atividades desenvolvidas pela FCP e INCRA, com a atuação do MPF nas ACPs e com todas as reivindicações das lideranças de Mata Cavalo, o obstáculo de maior significado é o conflito de interesses pela área, uma vez que dezenas de particulares permanecem em disputa por um território que é historicamente dos negros.

Os negros, por serem a parte mais fraca da relação social na luta pela terra, permanecem em invisibilidade, pois conforme acentua Gusmão (1995: 70-71): "[...] O confronto pela terra e o conflito entre realidades diversas revelam assim, a existência de muitas linguagens próprias desse mundo singular e prenhe de sentidos. Um mundo cujo eco não é ouvido pela sociedade inclusiva."

Isto se dá porque mesmo diante do reconhecimento normativo do território, reforçado pela Constituição Federal, o Estado brasileiro não o efetiva, uma vez que ao retardar o processo de titulação do quilombo Mata Cavalo, 
permite que conflitos agrários continuem existindo, que vidas continuem sendo ameaçadas, o desenvolvimento econômico, social e cultural seja tolhido, mantendo os negros no campo da invisibilidade e vulnerabilidade social.

Mata Cavalo é um exemplo da realidade dos quilombos no projeto do Estado brasileiro: preterido na adoção da política pública de titulação de seu território, desconhecidos quanto à sua realidade no imaginário social e cenário de violências de toda ordem.

Nesse sentido, o Estado brasileiro viola os direitos humanos dos quilombolas de Mata Cavalo ao não garantir o direito efetivo ao território negro e a permitir que as ondas de violência se perpetuem, atingindo os atributos básicos de dignidade, previstos nos documentos internacionais e nacionais, pelo que reforçamos a urgência da titulação, uma vez que as terras de quilombo, ao serem tituladas, saem do mercado de terras e por consequência, deixam de ser alvo de disputa, de modo a garantir a vida digna aos que lutam por mais de cento e trinta e quatro anos pelo direito ao acesso à terra.

\section{Considerações Finais}

Compreende-se que as violações de direitos humanos contra os negros não tiveram fim com a abolição. As injustiças sociais se perpetuam até os dias atuais, sobretudo aos quilombolas. As lutas incessantes por direitos trouxeram resultados no ordenamento jurídico, como o reconhecimento do território étnico como fundamental e o dever do Estado em efetivá-lo. Nesse sentido, é importante considerar que não somente o direito a titulação da terra é necessário, mas parte-se de sua garantia para que outros correlatos, como o desenvolvimento econômico, social e cultural possam ser garantidos e promovidos.

O Estado, ao negar os direitos inerentes à dignidade humana dos quilombolas, que passa fundamentalmente pelo regularização das terras quilombolas, permite que a sociedade também o faça, como ocorre em Mata Cavalo, podendo-se afirmar que o Brasil é um grande violador dos direitos humanos dos quilombolas, como apurado pelo relatório da missão ao Estado de Mato Grosso.

A violência praticada por terceiros interessados nas terras do quilombo são resultado da inércia estatal e da influência que tais interesses implicam nos processos de tomada de decisão. São cerca de cento e trinta e quatro anos de expropriações e quatorze anos de espera pela regularização fundiária junto ao INCRA pelas mais de quatrocentas famílias que compõem Mata Cavalo cujo direito humano à titulação de seu território se mantém negligenciado pelo Estado brasileiro. Todavia, a resistência se mantém presente no cotidiano e reforça a etnicidade local e a esperança pela vida digna. 
ACEVEDO MARIN, Rosa Elizabeth. Terras e afirmação política de grupos rurais negros na Amazônia. In: O’DWYER, Eliane Cantarino (Org.). Terra de quilombos. ABA - Associação Brasileira de Antropologia. Rio de Janeiro: Decania CFCH/UFRJ, 1995. p. 79-94.

; CASTRO, Edna. No caminho de pedras de Abacatal: experiência social de grupos negros no Pará. 2. ed. Belém: NAEA/UFPA, 2004.

ALCÂNTARA, José Luiz; FONTES, Rosa Maria Oliveira. A formação da propriedade e a concentração de terras no Brasil. Revista de História Econômica \& Economia Regional Aplicada, Juiz de Fora, v. 4, n. 7, p. 63-85, jul./dez. 2009. Disponível em: <http://www.ufjf.br/heera/files/2009/11/ESTRUTURA-FUNDI\%C3\%81RIAze-luispara-pdf.pdf>. Acesso em: 12 ago. 2017.

ALMEIDA, Alfredo Wagner Berno de. Os quilombos e as novas etnias. In: Quilombos: identidade étnica e territorialidade. O'DWYER, Eliane Cantarino (Org.). Rio de Janeiro: Editora FGV, 2002. p. 43-81.

ASSOCIAÇÃO BRASILEIRA DE ANTROPOLOGIA. Carta de Ponta das Canas. Documento de Trabalho da Oficina Sobre Laudos Antropológicos realizada pela $A B A$ e NUER/UFSC. Florianópolis, 18 nov. 2000. Disponível em: <http://www.abant.org.br/conteudo/oo1DOCUMENTOS/DocumentosABA/ca rtacanas.pdf $>$. Acesso em: 20 nov. 2017.

BANDEIRA, Maria de Lourdes. Terras negras: invisibilidade expropriadora. Terras e territórios de negros no Brasil. Textos em Debate - Publicação do Núcleo de Estudos sobre Identidade e Relações Interétnicas - UFSC, Santa Catarina, ano 1, n. 2, p. 7-23, 1991.

; DANTAS, Triana de Veneza Sodré e; MENDES, Elieth Barros. Mata Cavalo (MT). Relatório Antropológico. Projeto de Mapeamento $e$ Sistematização das Áreas de Comunidades Remanescentes de Quilombo. Ministério da Cultura. Fundação Cultural Palmares. Universidade de Cuiabá UNIC, 2006.

BARROS, Edir Pina de. Estudo Antropológico. Ação Civil Pública $n$. 2002.36.00.007491-8. $2^{\text {a }}$ Vara Federal. Tribunal Regional Federal da $1^{\text {a }}$ Região, 2007.

BELTRÃO, Jane Felipe; OLIVEIRA, Assis da Costa. Identidade, autonomia e direitos humanos: desafios à diversidade étnica no Brasil. Hendu - Revista Latino-Americana de Direitos Humanos, Belém, v. 2, n.1, p. 56-70, 2011.

BRASIL. Decreto $n^{\circ}$. 592, de 6 de julho de 1992. Atos Internacionais. Pacto Internacional sobre Direitos Civis e Políticos. Promulgação. Diário Oficial [da] República Federativa do Brasil, Brasília, 6 jul. 1992. Disponível em: < http://www.planalto.gov.br/ccivil_03/decreto/1990-1994/do592.htm>. Acesso em 25 ago. 2017.

BRASIL. Decreto $n^{\circ}$. 4.887, de 20 de novembro de 2003. Regulamenta e procedimento para identificação, reconhecimento, delimitação, demarcação e titulação das terras ocupadas por remanescentes das comunidades dos 
quilombos de que trata o art. 68 do Ato das Disposições Constitucionais Transitórias. Diário Oficial [da] República Federativa do Brasil, Brasília, 20 nov. 2003. Disponível em: < http://www.planalto.gov.br/ccivil_03/decreto/2003/D4887.htm\#art25>. Acesso em: 26 ago. 2017.

BRASIL. Decreto $n^{\circ}$. 5.051, de 19 de abril de 2004. Promulga a Convenção n. 169 da Organização Internacional do Trabalho - OIT sobre Povos Indígenas e Tribais. Diário Oficial [da] República Federativa do Brasil, Brasília, 19 abr. 2004. Disponível em: < http://www.planalto.gov.br/ccivil_03/_ato20042006/2004/decreto/d5051.htm>. Acesso em 26 ago. 2017.

BRASIL. Decreto $n^{\circ}$. 65.810, de o8 de dezembro de 1969. Promulga a Convenção Internacional sobre Todas as Formas de Discriminação Racial. Brasília, o8 de dezembro de 1969. Diário Oficial [da] República Federativa do Brasil, Brasília, 8 dez. 1969. Disponível em: <http://legis.senado.gov.br/legislacao/ListaTextoIntegral.action?id=94836>. Acesso em: 25 ago. 2017.

BRASIL. Instituto Nacional de Colonização e Reforma Agrária. Superintendência Regional de Mato Grosso. Processo administrativo de regularização fundiária INCRA/SR-13/N. 54240.001538/2004-70. Requerente: Associação Sesmaria Boa Vida Quilombo Mata Cavalo. Requerido: Instituto Nacional de Colonização e Reforma Agrária. Cuiabá, 13 ago. 2004.

BRASIL. Supremo Tribunal Federal. Ação Direta de Inconstitucionalidade $n^{\circ}$. 3239. Requerente: Democratas. Requerido: Presidente da República. Relator: Ministro Antonio Cezar Peluso. Disponível em: <http://redir.stf.jus.br/estfvisualizadorpub/jsp/consultarprocessoeletronico/C onsultarProcessoEletronico.jsf?seqobjetoincidente $=2227157>$. Acesso em: 19 mar. 2017.

CANÇADO TRINDADE, Antônio Augusto. Tratado de Direito Internacional dos Direitos Humanos. v. 3. 2. ed. rev. e atual. Porto Alegre: Sergio Antonio Fabris Editor, 2003.

GILBERT, Jérémie. Direito à terra como direito humano: argumentos em prol de um direito específico à terra. Tradução Thiago Amparo. SUR Revista Internacional de Direitos Humanos, São Paulo, v. 10, n. 18, p. 121-143, jun. 2013 .

GUSMÃO, Neusa Maria Mendes de. Caminhos transversos: território e cidadania negra. In: O’DWYER, Eliane Cantarino (Org.). Terra de quilombos. ABA - Associação Brasileira de Antropologia. Rio de Janeiro: Decania CFCH/UFRJ, 1995. p. 61-78.

HELD, Thaisa. MATA CAVALO: a luta pela terra e a violação do direito humano ao território quilombola em Nossa Senhora do Livramento-MT. Tese de Doutorado, Direito, UFPA, 2017.

LEITE, Ilka Boaventura. Quilombos e quilombolas: cidadania ou folclorização? Horizontes Antropológicos, Porto Alegre, ano 5, n. 10, p. 123-149, maio 1999. 
MENDONÇA, Renato. A influência africana no português do Brasil. São Paulo: Nacional, 1935.

ORGANIZAÇÃO DAS NAÇÕES UNIDAS. Declaração Universal dos Direitos Humanos. $\quad$ Disponível em: < http://www.ohchr.org/EN/UDHR/Documents/UDHR_Translations/por.pdf>. Acesso em: 27 ago. 2017.

PLATAFORMA BRASILEIRA DE DIREITOS HUMANOS ECONÔMICOS, SOCIAIS E CULTURAIS. Relatório da Missão ao Estado de Mato Grosso. (Realizada entre 15 e 24 de agosto de 2004). Relatoria Nacional para o Direito Humano ao Meio Ambiente. Rio de Janeiro, 2005. Disponível em: < http://www.dhnet.org.br/dados/relatorios/r_dhescas_br/missao_2004_mt_d hesc_meio_ambiente.pdf $>$. Acesso em: 27 ago. 2017.

SATO, Michèle et al. Comunidade Quilombola de Mata Cavalo. Cuiabá: GPEAUFMT, Série Cadernos Pedagógicos, 2010. Disponível em: < http://gpeaufmt.blogspot.com.br/p/materiais-e-apoio-pedagogico.html>. Acesso em: 23 ago. 2017.

SOLAZZI, José Luís, WOLKMER, Antonio Carlos. Interpretação constitucional, pluralismo jurídico e a questão quilombola: uma abordagem descolonial e intercultural do Decreto $\mathrm{N}^{\circ} 4.889 / 2003$ e da ADI 3239. In: WOLKMER, Antonio Carlos; FILHO, Carlos Frederico Marés de Souza; TARREGA, Maria Cristina Vidotte Blanco (Coords.). Os direitos territoriais quilombolas: além do marco temporal. Goiânia: Ed. da PUC Goiás, 2016, p. 31-53.

TRECCANI, Girolamo Domenico. Terras de quilombo: caminhos e entraves do processo de titulação. Belém: Secretaria Executiva de Justiça. Programa Raízes, 2006. 